\title{
EXÉGESIS E IDEOLOGÍA EN EL JUDAÍSMO DEL S. I HÉROES, HEROÍNAS Y MUJERES *
}

N. FERNÁNDEZ MARCOS

CSIC. Madrid

\section{INTRODUCCIÓN}

Una de las actividades culturales más comunes entre los pueblos que han accedido a cierto grado de civilización es la de escribir su historia para la posteridad. En la antigüedad, tanto campañas militares como períodos enteros de un reinado quedaban consignados por escrito, y por consiguiente interpretados, en los anales o crónicas de los archivos reales. Hoy sabemos además que la historia no termina de escribirse nunca. Y por eso nos hallamos en una permanente revisión del pasado en la que viejos ídolos se destruyen mientras se rescatan del olvido personajes maltratados por la historiografía anterior. Es decir, el pasado se rehace interpretándolo desde el presente. Surgen lecturas polivalentes de los mismos documentos y métodos distintos de aproximación a los textos según sea la perspectiva del que escribe. Por eso se puede hablar de una historia económica, historia social, historia de las instituciones, de las ideas, o historia de la vida cotidiana.

Israel no fue distinto de los otros pueblos del Antiguo Oriente, aunque tampoco se puede ocultar que entendió su propia historia como un proceso de elección divina y que la escribió desde esta perspectiva. Lo cual no quiere decir que no recurriese también a una actualización y reescritura periódica de esa historia cuando las condiciones culturales del momento así lo exigían. Uno de los períodos más creativos en nuevas interpretaciones de la historia fue la época helenística. Más que a los historiadores judeohelenísticos

* Este artículo ha sido publicado simultáneamente en las Actas del VIII Congreso internacional de la Asociación Italiana para el Estudio del Judaísmo (AISG) sin la advertencia, exigida por el autor, de que ya estaba impreso en Sefarad. 
me estoy refiriendo a la literatura apocalíptica. Esto fue posible porque además de la Escritura como revelación, los judíos de esta época apelaban a otra revelación secreta, no escrita, que completaba la anterior y sobre todo desvelaba el sentido final de la historia '. Esta revelación secreta implicaba una nueva lectura de las Escrituras, una reinterpretación del pasado a la luz de los acontecimientos contemporáneos. Y si bien no tenemos en el período helenístico una historia económica o social porque aún no se habían diversificado las ciencias históricas, nos encontramos en cambio con abundantes resúmenes o sumarios del pasado de Israel desde perspectivas distintas: visiones heroicas y litúrgicas de la historia, visiones zoomórficas y tipológicas en las que las personas, instituciones o acontecimientos se describen y relatan como modelos o prefiguraciones de personas o acontecimientos contemporáneos. T. Rajak ha llegado a decir que "On any broader conception of history, intertestamental Judaism is a culture that is historically-minded and notably prolific in historical thought" 2. No hay que perder de vista que en la antigüedad no tenían el mismo concepto de rigor histórico que en los tiempos modernos y consideraban las expansiones o reescrituras de la Biblia como otra forma de decir lo mismo según fuera la condición del destinatario, a la manera de las Biblias historiadas o moralizadas de la Edad Media ${ }^{3}$.

Estos autores intentan unificar la tradición en torno a un texto base bíblico. Como ha observado Alexander ${ }^{4}$, cumplen una doble función a la vez: exegética, ya que intentan clarificar los pasajes oscuros y limar las inconsistencias del texto, y creativa al incorporar material extrabíblico a la Escritura impidiendo de esta forma la fragmentación de la tradición.

Son también múltiples las formas literarias en las que los judíos

\footnotetext{
' Cf. D. PatTe, Early Jewish Hermeneutic in Palestine, Missoula, Montana 1975, págs. 205-207.

${ }^{2}$ T. RAJAK, "The Sense of History in Jewish Intertestamental Writing", OS 24 (1986) 124-145, 130. Y en pág. 132: "The retelling of Biblical history, with expansions, contractions and even modifications was everywhere, as I have said, a major branch of literary activity in the period, notwithstanding the special status held by the canonical books and the obligation not to add or substract emphasized by Josephus".

${ }^{3}$ Cf. K. Reinhardt y H. Santiago Otero, Biblioteca Biblica Ibérica Medieval, Madrid 1986, págs. 27-29 y 81-83. La Biblia se utiliza en la General Estoria al servicio de la historia universal junto con Josefo y otras fuentes de la antigüedad.

${ }^{4}$ Ph. S. Alexander, "Retelling the Old Testament", en D. A. Carson - H. G. M. Williamson (eds.), en It is Written: Scripture Citing Scripture. Essays in Honour of Barnabas Lindars, Cambridge 1988, 99-121, 118.
} 
plasman sus interpretaciones del pasado en el período helenísticoromano. Algunas de ellas tienen como objetivo la presentación ante la sociedad helenística del pueblo de Israel y de su historia. De este asunto me ocupé en otro lugar 's. Pero hay que señalar entre otras el Elogio de los antepasados (Ben Sira 44-50), en donde el autor del libro reúne por primera vez a los "héroes de Israel" en una secuencia seguida poniéndolos como modelo de comportamiento para sus contemporáneos. Al igual que los héroes de la Grecia clásica, éstos son los hombres famosos ( $\dot{\varepsilon} v \delta$ ó ous $_{4} 4,1$ ), los que han dejado huella

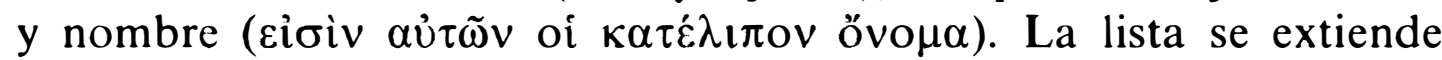
desde Adán hasta el Sumo Sacerdote Simón, contemporáneo del autor. Enoc y Noé, Abrahán, David y Salomón, Moisés y Elías son presentados como modelos de imitación para los piadosos de Israel que están viviendo en medio de un pueblo perverso y dominador.

Curiosamente, y a pesar de la extensión del elogio, no aparece ni una sola mujer en la lista, aunque no faltaban en la historia bíblica mujeres heroicas como Débora, o mujeres ejemplares como Sara. Así pues, entre las "figuras ideales" o paradigmáticas del judaísmo antiguo difícilmente encontramos el diseño tipológico en su versión femenina. Al contrario, siempre se tratará del justo, el visionario, el hombre divino, el ungido, el levita, el escriba, el mártir o el carismático ${ }^{6}$.

Sin embargo, y pese a encontrarnos en el ámbito de una sociedad patriarcal que tiene réplicas elocuentes en el mundo grecorromano ?, en la historia de Israel no falta un lugar para las heroínas. Narraciones como las de Judit, Ester o Susana son de inequívoca exaltación femenina. Es más, la historia de Susana parece influida por la narración de José y la mujer de Putifar, pero invirtiendo los papeles masculino y femenino en lo relativo al modelo ético de castidad ${ }^{*}$.

${ }^{5}$ N. FERnández Marcos, "Interpretaciones helenísticas del pasado de Israel", Cuadernos de Filología Clásica VIII (1975) 157-186, en especial págs. 163-166.

${ }^{6}$ Cf. W. E. Nickelsburg - J. Collins (eds.), Ideal Figures in Ancient Judaism, Chico CA 1980, y H. W. Hollander, Joseph as an Ethical Model in the Testaments of the Twelve Patriarchs, Leiden 1981 y G. MAYER, Die jüdische Frau in der hellenistischrömischen Antike, Stuttgart 1987.

7 Cf. J. LeIPOLDT, Die Frau in der Antike und im Urchristentum, Gütersloh 1962, págs. 13-49.

${ }^{8}$ G. W. E. Nickelsburg, Jewish Literature Between the Bible and the Mishnah, Filadelfia 1981, pág. 26. Y para Judit cf. ibid. pág. 108. Judit usa sus armas femeninas, su atractivo, para derrotar al enemigo: "Que no cayó el más poderoso de ellos a manos de jóvenes, ni lo golpearon los titanes, ni gigantes enormes lo asaltaron, sino Judit, hija de Merarí, con la belleza de su rostro lo deshizo". Traducción mía en F. Cantera y M. Iglesias, Sagrada Biblia, Madrid 1979², pág. 910. 
En el siglo primero pervive esta tradición de mujeres ilustres del pasado de Israel. El autor de José y Asenet no encuentra mejores palabras para recomendar a la egipcia Asenet que describirla «alta como Sara, grácil como Rebeca y hermosa como Raquel» ". Y el autor del Liber Antiquitatum Biblicarum, que sobresale por su feminismo, llega a designar a Débora con el título "mujer de Dios", construido sobre el modelo de «hombre de Dios» (cf. 1 Samuel 9,6 ss.) y describe a Seila, la hija única de Jefté ofreciéndose libremente al sacrificio, como una réplica de Isaac (Gen 40,2) antes de reposar en "el seno de sus madres" ( $L A B$ 40,4), expresión traspuesta también del masculino al femenino ${ }^{10}$.

Sabido es que junto a estos reconocimientos leales de heroínas en personajes femeninos del Antiguo Testamento surgió ya en la literatura sapiencial una corriente de misoginia que puede sintetizarse en algunos de los pasajes más radicales de Ben Sira como 25,24: "De la mujer procede el principio del pecado; por ella morimos todos", o 42,14: «Mejor es la maldad del hombre que la bondad de la mujer" —según el hebreo-, "que una mujer benéfica" —según Septuaginta-, corriente que se acentúa todavía más en la versión griega de Proverbios ".

\footnotetext{
${ }^{9}$ Apócrifos del Antiguo Testamento, bajo la dirección de A. Díl:z Macho, III, Madrid 1982, pág. 209. Josefo desarrolla tres modelos de heroínas bíblicas que coinciden con las mujeres mencionadas en José y Asenet: Sara la mujer tradicional, Rebeca la mujer segura de sí misma y Raquel la romántica, cf. B. HALPERN AMARN, "Portraits of Biblical Women in Josephus' Antiquities", JJS 39 (1988) 143-170. También desarrolla dos modelos de mujeres fatales: la madianita, seductora y engañosa y la mujer de Putifar, abrasada por la pasión sexual.

${ }^{10}$ Pseudo-Philon. Les Antiquités Bibliques, tome II, Introduction littéraire, commentaire et index par Ch. PERROT y P. M. BOGAERT avec la collaboration de D. J. Harrington, Paris 1976, pág. 52. El texto está tomado de Pseudo-Philon, tome I, Introduction et texte critiques par D. J. HARRINGTON, traduction par J. CAZEAUX, Paris 1976: «Et factum est dum appropinquarent dies mortis eius, misit et congregavit omnes populos, et dixit ad eos: Audite nunc populi mei. Ecce ego moneo vos tanquam mulier Dei, et illumino vos tanquam ex femineo genere, et obaudite mihi quasi matri vestre et intendite verbis meis tanquam morituri et ipsi" (LAB 33,1). Cf. Ph. TRIBLE. "A Daughter's Death: Feminism Literary Criticism and the Bible", en M. P. O'ConNor - D. N. Freedman (eds.), Background for the Bible, Winona Lake, Indiana 1987, 1-14 y P. W. VAN DER HORST, “Portraits of Biblical Women in PseudoPhilo's Liber Antiquitatum Biblicarum", JSP 5 (1989) 29-46.

$"$ Cf. M. Philonenko, "Essénisme et misogynie», Comptes rendus des séances de l'Académie des Inscriptions et Belles Lettres 1982, 339-353. Ver por ejemplo Prov. 5,3-

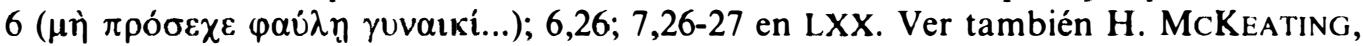
"Jesus ben Sira's Attitude to Women", ExpTim 85 (1973-1974) 85-87 y M. GILBERT, “Ben Sira et la femme», RTL 7 (1976) 426-442.
} 
A continuación voy a fijarme en tres momentos de la literatura judía del s. I a. C. - s. I d. C., en los que la asociación de la mujer con el mal, el sexo o el diablo conduce a conclusiones que dejan malparada la condición femenina, con consecuencias importantes para el pensamiento ulterior y en especial para la antropología judeo-cristiana. Me refiero a la Vida Griega de Adán y Eva, los Testamentos de los Doce Patriarcas y el Testamento de Job. No es fácil encontrar acuerdo entre los especialistas sobre la fecha y lugar de composición de un escrito intertestamentario. Sin embargo, podemos convenir que estas tres obras ocupan un lugar preferente en el judaísmo del s. I, si excluimos las interpolaciones cristianas. Prefiero mantener un marco cronológico flexible por las dificultades de datación y por el complejo proceso de formación literaria y de transmisión textual que las caracteriza. Por otro lado, tampoco me preocupa demasiado el no ceñirme estrictamente al concepto de judaísmo palestinense, porque hoy no podemos trazar una línea divisoria tajante entre judaísmo helenístico y judaísmo palestinense, ya que también la población de Palestina estaba altamente helenizada. Es más, muchas veces el lugar de composición de una obra sigue siendo mera conjetura y los conceptos relativos a los grupos o modelos de judaísmo existentes en estos siglos no siempre se emplean con precisión. Se habla con frecuencia de "religiosidad popular", de "judaísmo no sectario", de "esenismo" o de "círculos fariseos", de "círculos apocalípticos" etc. Lo que importa es acercarse a estos textos de una forma descriptiva o inductiva sin encuadrarlos de antemano en algunos de los grupos o sectas conocidos. Pues hay que tener en cuenta que es muy poco lo que conservamos de la producción literaria de la época y que a medida que aumenta nuestro conocimiento de ella es preciso aceptar un pluralismo mayor en el judaísmo del s. I, un pluralismo que muchas veces sólo adivinamos a través de ráfagas fugaces que proyectan estos escritos.

\section{Vida griega de Adán y Eva}

Uno de los comentaristas más recientes del libro del Génesis, C. Westermann, concluye al interpretar la narración de Gen 2-3: «Es ist bedeutsam, dass wir in unserer gegenwärtigen Kulturepoche im wesentlichen mit dem übereinstimmen, was Gn 2 zu dem Verhältnis 
von Mann und Frau sagt" '2. Y lo ilustra con ejemplos de relatos de tribus contemporáneas de África Occidental.

Previo a todo pensamiento institucional en ese acontecimiento primordial, el Yahvista habla de la comunidad entre hombre y mujer. La cuestión de la seducción del hombre por la mujer apenas está apuntada ${ }^{13}$. Sin embargo, en la Vida Griega de Adán y Eva la culpabilidad de Adán queda muy atenuada - cuando no es prácticamente exculpado-, recayendo toda la responsabilidad de la transgresión sobre Eva. En 7,1 dice Adán a Set: "Cuando nos hizo Dios a mí y a vuestra madre por cuya causa muero" ${ }^{14}$. O el reproche de Adán en 21,6: «Mujer perversa ( $\pi 0 v \eta \rho \alpha ́)$, ¿qué has perpetrado contra nosotros? Me has arrebatado la gloria de Dios». Y la confesión de Eva en 32,2: «He pecado, oh Dios, he pecado, oh Padre de todas las cosas, he pecado contra ti, he pecado contra tus ángeles elegidos, he pecado contra los querubines, he pecado contra tu trono inconmovible, he pecado, Señor, he pecado mucho, he pecado en tu presencia y todo pecado ocurrió por culpa mía en la creación» ${ }^{15}$. Frente a la exaltación de Adán, que se pone de manifiesto en los grandes honores que recibe en sus funerales, a los que se desplaza Dios en persona con toda su corte celestial, el destino de Eva es mucho más modesto y vuelve por simetría exegética a unirse a su marido de donde fue tomada. Es decir, su destino está incluido en el de Adán 'to.

12 C. Westermann, Genesis, Biblischer Kommentar, Altes Testament, I, Genesis 1-11, Neukirchen - Vluyn 1974, pág. 316.

${ }^{13}$ C. Westermann, Genesis, pág. 340: “das Zusammenhalten dieser Gemeinschaft kann, weil der Mensch fehlsam ist, auch ein Zusammenhalten in der Verfehlung sein".

${ }^{14}$ Citas y texto griego según la edición de D. A. BlRtrand, La Vie grecque d'Adam et Eve, Paris 1987. Ver también 9,2 y 14,2. Cierta atenuación de la culpa de Eva tal como se refleja en $V A E$ 15-30 se debería a que esa narración, originalmente independiente como testamento de Adán, fue introducida posteriormente por el editor en la $V A E$, cf. J. R. LEvison, "The Exoneration of Eve in the Apocalypse of Moses 15-30». JSJ 20 (1989) 135-151.

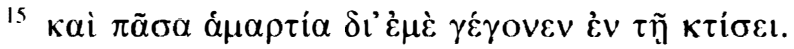

16 Cf. D. A. Birtrand, La Vie grecque d'Adam et Ève, pág. 59 y D. A. Birtrani), "Le destin post mortem des Protoplastes selon la Vie grecque d'Adam et Ève", en $\mathrm{La}$ littérature intertestamentaire (Coloquio de Estrasburgo, octubre 1983), Paris 1985, 109-118. Esta tendencia a atribuir a Eva la responsabilidad del pecado se toma de nuevo en la Vida latina de Adán y Eva 3.18.35 («Señor Dios, pásame sus dolores [de Adán], porque fui yo quien pecó»), y 44 (cf. mi traducción en Apócrifos del Antiguo Testamento, II, Madrid 1983, págs. 338-352) y especialmente en 1 Timoteo 2,13-15: 


\section{Testamentos de los doce Patriarcas}

En el relato original de Gen 6,1-4, según el cual los hijos de Dios se unen con las hijas de los hombres, no hay asignación clara de culpa. Sencillamente se dice que éstas eran hermosas y que los seres celestes se sintieron atraídos por ellas. En el Libro de los Vigilantes (1 Enoc 6,1-5) parece que la responsabilidad está de parte de los Vigilantes, quienes secundan a su jefe Semiaza y se juramentan para no cambiar de opinión ${ }^{17}$. A continuación les enseñarán las distintas artes y los encantamientos (1 Enoc 8,1-4). En Jubileos 4,15 descienden a "enseñar al género humano a hacer leyes y justicia sobre la tierra" "18.

En cambio, en el Testamento de Rubén la culpa recae de nuevo sobre las mujeres que son malas ( $\pi$ ov $\eta \rho \alpha i ́)$ y seducen con engaños a los hombres como las sirenas, lo mismo que sedujeron a los Vigilantes: "1 Perversas son las mujeres, hijos míos: como no tienen poder o fuerza sobre el hombre, lo engañan con el artificio de su belleza para arrastrarlo hacia ellas. ${ }^{2} \mathrm{Al}$ que no pueden seducir con su apariencia lo subyugan por el engaño. ${ }^{3}$ Sobre ellas me habló también el ángel del Señor y me enseñó que las mujeres son vencidas por el espíritu de la lujuria más que el hombre. Contra él urden maquinaciones en su corazón, y con los adornos lo extravían comenzando por sus mentes. Con la mirada siembran el veneno y luego lo esclavizan con la acción. ${ }^{4}$ Una mujer no puede vencer por la fuerza a un hombre, sino que lo engaña con artes de meretriz. ${ }^{5}$ Huid, pues, de la fornicación, hijos míos, y ordenad a vuestras mujeres e hijas que no adornen sus cabezas y rostros, porque a toda mujer que usa de engaños de esta índole le está reservado un castigo eterno. ${ }^{6}$ De este modo sedujeron [ $\left.\varepsilon^{\prime} \theta \varepsilon \lambda \xi \alpha v\right]$ a los Vigilantes antes del diluvio. Como las estaban viendo tan continuamente, se encen-

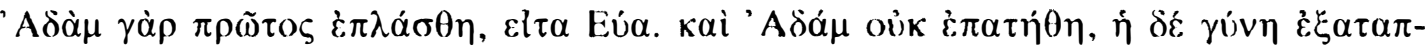

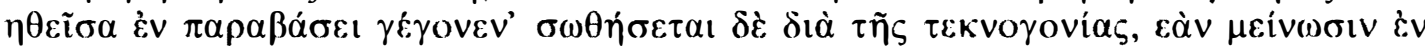

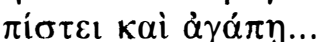

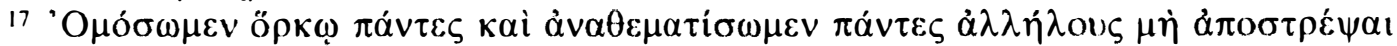

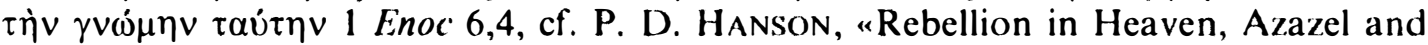
Euhemeristic Heroes in 1 Enoch 6-11", JBL 96 (1977) 195-233.

18 Apócrifos del Antiguo Testamento, II, pág. 92. Es decir, en el Libro de los Jubileos al contrario que en $I E n o c$, los Vigilantes no bajan a la tierra a quebrantar la Ley de Dios: "Furono sedotti dalle donne mentre erano sulla terra, non mentre erano in cielo" dirá L. Fusella en Apocrifi dell'Antico Testamento, I, Torino 1981, pág. 194.
} 
dieron en deseos por ellas y concibieron el acto ya en sus mentes. Se metamorfosearon en hombres y se aparecieron a ellas cuando estaban con sus maridos. ${ }^{7}$ Las mujeres sintieron interiormente atracción hacia tales imágenes y engendraron gigantes. Los Vigilantes, en efecto, se les aparecieron con un tamaño que llegaba hasta el cielo" ${ }^{19}$. En consecuencia, hay que guardar los sentidos de toda mujer y prohibir a éstas estar a solas con el hombre, porque los encuentros continuos son para ellas un mal incurable y para nosotros un eterno reproche de Beliar (TestRub 6,1-3). Todos los males le han acaecido al patriarca Rubén por su cohabitación con Bilhah, la concubina de su padre. El texto bíblico (Gen 25,22 y 49,4) sólo menciona el hecho, pero el Testamento de Rubén $(3,10-15)$ introduce el motivo novelesco de la mujer en el baño como elemento de seducción -ausente en el libro del Génesis- que encontrará su forma clásica en la Historia de Susana (15-17) y que está tomado de la novela helenística ${ }^{20}$.

La historia brevemente apuntada en Gen 39,7-18 de José resistiendo la solicitación de la mujer de Putifar se convierte en la primera parte del Testamento de José (TestJos 2-10) en un combate (ả $\gamma \omega \dot{v})$ de José con la mujer egipcia que evoca el combate cuerpo a cuerpo de Job con Satán en el Testamento de Job. El Génesis describe brevemente una escena de seducción. En el Testamento de José estas escenas se suceden gradualmente con amplificaciones antológicas que incorporan todos los tópicos de la literatura erótica y de la psicología femenina. La mujer egipcia recurre sucesivamente a las amenazas, las promesas, la seducción con engaño, la adulación, el chantaje, los filtros de amor y las pócimas mágicas, los encantamientos, la simulación de enfermedad, la calumnia, o la amenaza de suicidio, con el fin de hacer perder a José el control de sí mismo, hasta que éste descubre que es el espíritu de Beliar el que le está perturbando (TestJos 7,4).

${ }^{19}$ Testamento de Rubén 5,1-7 en Apócrifos del Antiguo Testamento, V, Madrid 1987, pág. 34. Nótese que para la seducción de los Vigilantes (TestRub 5,6$)$ se usa el mismo verbo poético ( $\theta \dot{\varepsilon} \lambda \gamma \varepsilon \iota v)$ que usa Homero para las sirenas en Odisea 12,39 ss., cf. H. W. Hollander - M. DE Jonge, The Testaments of the Twelve Patriarchs. A Commentary, Leiden 1985, pág. 103. "Ormai la donna è veramente sentita come la causa presente del peccato e quindi dell'impurità e della morte» dice P. SACCHI en Apocrifi dell' Antico Testamento, I, Torino 1981, pág. 774, $\mathrm{n}^{\circ} 1$.

${ }^{20}$ Cf. M. Philonenko et alii, La Bible. Écrits Intertestamentaires, Paris 1987, pág. 821. Véase el mismo motivo de la seducción en el baño en Jubileos 33,1-9. 
En este análisis de la seducción femenina aparece ya una sensibilidad para describir los sentimientos y conflictos interiores, propia de la novela helenística. No sólo afloran estos movimientos subterráneos de los sentimientos humanos sino también los tópicos principales de la filosofía moral helenística, en concreto el del hombre justo acechado por la mujer perversa ${ }^{21}$

Esta mujer que seduce a José siempre aparece bajo la denominación de "la mujer egipcia" tanto en el TestRub 4,9 como de una forma casi obsesiva en el TestJos 3,6; 4,3; 8,1.5; 16,5: En TestJos 7,4 , José cae en la cuenta de que es Beliar el que la está molestando ( $\dot{\varepsilon} \vee \chi \lambda \bar{\varepsilon} \tilde{)})$, verbo que con frecuencia se emplea para la posesión demoníaca. Egipto, como enemigo secular de Israel, también se identifica con frecuencia con los poderes del mal. Pero esta vinculación de la mujer con Satán se verá todavía más clara en el documento al que ahora nos volvemos, el Testamento de Job.

\section{Testamento de Job}

El Testamento de Job nos presenta a este héroe bíblico, modelo de paciencia, como un atleta divino que tiene que habérselas en la palestra con el propio Satán. Así se expresa su contrincante al confesar su derrota después de que Job ha resistido sus múltiples y taimadas embestidas: "Entonces salió de detrás de mi mujer y de pie dijo llorando: Mira, Job, he perdido y me retiro de ti que eres carne, yo que soy espíritu. Tú estás en la desgracia y yo en una gran turbación. Pues te has convertido en un atleta luchando con otro atleta y como el que derriba al otro. El que está encima hace callar al que está debajo haciéndole morder el polvo y quebrando todos sus miembros, mientras que el que está debajo muestra su coraje y no ceja, el que está encima lanza grandes gritos. Lo mismo tú, Job. Estabas debajo y en desgracia, pero has vencido en los combates que emprendí contra ti» ${ }^{22}$.

${ }^{21}$ Cf. M. Pilloontinko et alii, La Bible, págs. 920 ss. y H. W. Hollander - M. DE Jonge, The Testaments of the Twelve Patriarchs, pág. 370. Ver también la monografía

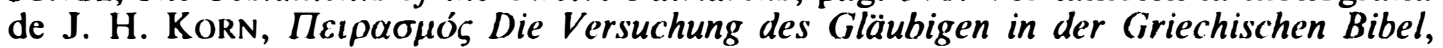
Stuttgart 1937.

${ }^{22}$ S. P. Brock (ed.), Testamentum Iobi, Leiden 1967, págs. XXVII, 2-5. La traducción es mía. La metáfora de morder el polvo alude a la lucha grecorromana cuerpo a cuerpo en pozos de arena. El combate cuerpo a cuerpo con el diablo constituirá uno de los móviles del movimiento monástico de Egipto, que lleva la batalla al mismo campo del enemigo, el desierto. Está por examinar el influjo del Testamento de Job en esta concepción y praxis del monaquismo primitivo, sobre todo en Egipto. 
Ahora bien, Job sólo derrota a Satanás cuando éste sale de su escondrijo a campo abierto; antes ha tenido que sufrir sus continuos asaltos y añagazas cuando se le ha presentado primero disfrazado de mendigo (TestJob 6,4), y después de vendedor de agua $(7,1)$, de rey de los persas que reúne a todos sus maleantes para despojarlo $(17,2)$, de vendedor de pan $(23,1)$ que deshonra a la mujer de Job vendiéndole tres panes a cambio de su cabellera, que le ha cortado en público $(24,10){ }^{23}$.

Por fin se disfraza de la propia mujer de Job: « que está detrás de ti perturbando tus razonamientos para engañarme a mí también?» (TestJob 26,6).

La protesta de la mujer de Job en el original hebreo «Maldice a Elohim y muérete" (Job 2,9), ya se había convertido en la traducción de Septuaginta en un largo lamento ${ }^{24}$. Y la respuesta de Job: «Has hablado com• una de las mujeres insensatas [å $\varphi \rho o ́ v \omega v]$ ", se trueca en TestJob 26,6 en una de esas frases lapidarias que culpan a las mujeres del extravío de sus maridos: "[el diablo] desea en efecto presentarte como una de esas insensatas $[\dot{\alpha} \varphi \rho o ́ v \omega v]$ mujeres que han extraviado la integridad [ả $\pi \lambda$ ó $\tau \eta \tau \alpha]$ de sus maridos» ${ }^{25}$.

23 La transfiguración de Satán en múltiples figuras y disfraces era creencia extendida en la antigüedad y se encuentra en 2 Cor 11,14. Siempre se emplea el mismo verbo

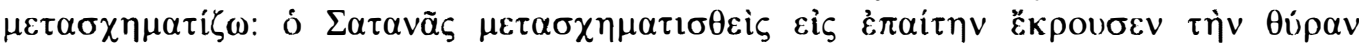

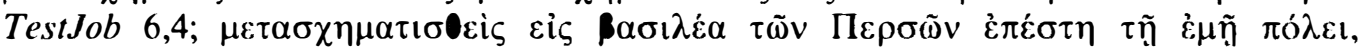

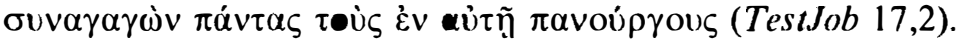

${ }^{24} \mathrm{Cf}$. Job LXX 2, 9a-e. Algunos piensan que esta adicción de LXX procede del Testamento de Job, pero aun admitiendo la estrecha conexión entre ambos no es fácil fijar la relación de dependencia: "The very close agreement between TJob 24:1-3 and the longer LXX form of Job 2:9 (Job 2:8b-9e LXX) does not clearly settle the uncertain textual relation between the two", R. P. SPITTLER en J. H. CHARIESWorTH (ed.), The Old Testament Pseudepigrapha, I, New York 1983, pág. 849.

${ }^{25}$ Sobre esta virtud en la Biblia griega y en el judaísmo intertestamentario cf. J. AмsтUTZ, АП ОТНГ. Eine begriffsgeschichtliche Studie zum jüdisch-christlichen Griechisch, Bonn 1968. Contrasta este tratamiento de la mujer de Job con el trato que reciben sus hijas al final del Testamento (TestJob 46-53) donde se las describe como extremadamente dotadas y circunspectas. Estas concepciones diferentes sobre la mujer se deberían a que la última parte del Testamento pertenecería a una fuente diferente procedente de un grupo social dominado por mujeres de tendencias extáticas y místicas, cf. P. W. VAN DER HORST, "The Role of Women in the Testament of Job", Nederlands Theologisch Tydschrift 40 (1986) 273-289; IDEM, "Images of Women in the Testament of Job", en M. A. KNIBB - P. W. VAN DER Horst (eds.), Studies on the Testament of Job, Cambridge 1989, 93-116. 
La misoginia en el judaismo del s. I llega a extremos insospechados en un escrito de la cueva 4 de Qumrán (4Q184) del que sólo conservamos un pequeño fragmento y que algunos autores han titulado Las trampas de la mujer y otros La mujer demoníaca. En este poema aparece la mujer como personificación de la necedad y del espíritu del mal: "Sí, ella es el principio de todos los caminos de perversión [v. 8] ... Sus ojos se fijan aquí y allá, y alza sus párpados con insolencia para mirar [al hombre] justo y seducirlo [vv. 13-14] ... para extraviar a los humanos en el camino de la Fosa y seducir con sus halagos a los hijos de los hombres [v. 17]".

El editor de este fragmento, del primer período de la época herodiana, piensa que es una advertencia contra los peligros de la prostituta ${ }^{26}$. A. Dupont-Sommer ${ }^{27}$ insiste en que es una diatriba más general y simple contra la malicia innata y las seducciones de la mujer que lleva hasta el extremo una corriente antifeminista bastante extendida en el s. I. Los rasgos que buena parte de la literatura sapiencial ${ }^{2 x}$ aplica a la descripción de la cortesana, la insensata $o$

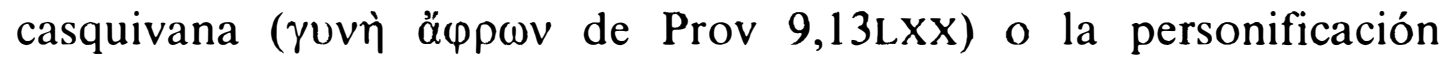
femenina de la necedad (Prov 7), los aplicaría el autor de este fragmento a la mujer en general, puesto que para él toda mujer es una cortesana que representa un peligro constante para el hombre. Probablemente esta figura encarna, a imagen de Lilit, al demonio de la seducción que mora en la oscuridad de los infiernos y sale para acechar al hombre ${ }^{24}$. En todo caso, cabe preguntarse al menos por

26 J. M. Allegiro, "The Wiles of the Wicked Women. A Sapiential Work from Qumran's Fourth Cave", PEQ 96 (1964) 53-55 y pl. XIII, Reeditado en Discoveries in the Judaean Desert of Jordan, V, Oxford 1968, n. 184, pl. XXVIII, quien restaura זונ|ה y no $\mathrm{n}[\mathrm{e}$ de Dupont-Sommer.

27 En La Bible. Écrits intertestamentaires, 443-447: "Tout au long de ce texte, malheureusement lacunaire, témoin d'une misogynic impitoyable qui a dû avoir cours un temps au moins à Qoumrân, chaque détail de la description de la femme et de ses actes concourt à faire d'elle, selon nous, l'ennemie physique et intelectuelle de l'homme, le 'principe de toutes les voies de perversion'», ibid., pág. 451, n. 17. Aunque el texto tiene paralelos indudables con las personificaciones de la insensatez del libro de los Proverbios, no se puede ignorar su proximidad a algunos párrafos del antifeminismo más radical que aparecen en los Testamentos de los Doce Patriarcas, como TestJud XV, 5-6, que presenta a la mujer como el principal enemigo del hombre.

${ }^{28}$ Job, Proverbios, Ben Sira, y muy especialmente Prov 9,13-18d (LXX).

29 Así lo cree J. M. Baumgartin, “On the Nature of the seductress in $4 \mathrm{Q} 184$ ", $R Q$ 57-58 (1991) 133-145. 
los efectos en la comunidad de Qumrán de esta personificación femenina de la necedad y del mal que intenta seducir al hombre justo.

\section{Conclusiones}

Hemos visto a lo largo de este breve recorrido la capacidad del judaísmo del s. I para reescribir la historia. Época enormemente rica en miradas al pasado para bucear en las posibles causas del mal y las tribulaciones que padecen; época fecunda también en proyecciones hacia el futuro en busca de una salida escatológica que dé sentido global a los distintos avatares históricos por los que están pasando. A imitación de los historiadores y mitógrafos helenísticos, los judíos han configurado también sus héroes y heroínas, paradigmas de comportamiento ético en circunstancias difíciles $u$ opresoras en las que su fidelidad a la Ley se ve amenazada. Y junto a estos personajes ilustres o figuras ideales, al indagar teológicamente en el origen del mal y de los desórdenes sociales, un sector de esta literatura nos presenta figuras de mujeres desempeñando un deslucido papel de antiheroínas, Eva y Sitis por ejemplo, cuando no, siendo las responsables directas de los males que aquejan a sus maridos, Adán y Job respectivamente, o instrumento directo de Satán, que no comprende en absoluto el mundo espiritual en el que se mueve Job ${ }^{30}$.

La mujer seductora de la Vida Griega de Adán y Eva se convierte en el Testamento de Rubén en la mujer perversa, que ha seducido cual sirena a los Vigilantes, un instrumento de Beliar, y de la que hay que huir como si fuera el mismísimo diablo; o la mujer fatal, la egipcia de la primera parte del Testamento de José, que no repara en medios, recurriendo incluso al crimen o la amenaza de suicidio, para violentar al hombre santo. Por fin, en $4 \mathrm{Q} 184$, los rasgos que la literatura sapiencial reservaba para la descripción de la prostituta o la personificación de la necedad en un contexto del esenismo más radical se concentran en esa figura mitológica que arrastra a los hombres hacia la muerte y el $\breve{S} e^{\text {'ôl }}$ (v. 10); el hombre justo de la secta siempre está acechado por la perversión en figura de mujer (vv. 14-16).

Es decir, los personajes masculinos del Antiguo Testamento, aunque parcialmente humanizados, no han perdido del todo su

${ }^{30}$ Cf. TestJob, 26-27 y 40. 
carácter heroico. Pero buena parte de los personajes femeninos se ven envueltos en las especulaciones sobre el origen del mal, y pasan de una responsabilidad compartida con el hombre, a ser la causa principal de los desórdenes sociales y del pecado. La vinculación de la mujer con el espíritu de la lujuria (TestRub 5,3), y más explícitamente con Satán o Beliar, convierten a ésta en un agente diabólico. Tertuliano llegará a formularlo con su conocida frase lapidaria: «femenina ianua diaboli»" ${ }^{11}$.

¿Cuáles son los presupuestos o factores que conducen a la exégesis por derroteros tan marcadamente misóginos? Una primera respuesta, y algunos así lo entienden, es atribuir a la secta de los esenios o a grupos próximos a los esenios todas las obras que hemos comentado ${ }^{32}$. Pero ni la Vida de Adán y Eva ni los Testamentos de los Doce Patriarcas ni el Testamento de Job son necesariamente esenios ${ }^{33}$. Pienso, sin embargo, que este tipo de exégesis tendenciosa afectaba a zonas más amplias de la sociedad judía del s. I que el judaísmo propiamente sectario. En su base estaba un dualismo escatológico, subyacente a gran parte de esta literatura, como consecuencia de la irrupción del pensamiento apocalíptico, un pensamiento que asociaba sexo (y por lo tanto la mujer), procreación y muerte en cuanto condiciones inherentes a este mundo por oposición al mundo venidero en el que se disfrutaba de un estado ideal de inmortalidad, donde ya no era necesario el sexo ni la procreación ${ }^{34}$. Precisamente en 1 Enoc 15,3-7 se formula esta vinculación estrecha entre sexo, procreación y muerte como componentes de la esfera

${ }^{31}$ Cf. L. StOCKER, Die Frau in der altem Kirche, Tubinga 1907, pág. 7, y Tertuliano, De cultu feminarum, I, 1.2.

${ }^{32}$ Así reacciona por ejemplo M. Philonenko en varios de sus escritos, y recientemente en La Bible, LXXXI, CXXIX y CXLIII.

${ }^{33}$ Para la Vida de Adán y Eva cf. D. A. Bertrand, La Vie Grecque d'Adam et Ève, págs. 32-37, pág. 37: “Mieux vaut dans ces conditions considérer que l'oeuvre émane d'un judaïsme doctrinalement peu différencié, comme l'était précisément celui du milieu alexandrin". Igualmente tanto para Becker como para Hollander y de Jonge, los Testamentos de los Doce Patriarcas no son sectarios (cf. H. W. Holl.ANDER - M. DE Jonge, The Testaments of the Twelve Patriarchs, pág. 24 y J. BECKER, Untersuchungen zur Entstehungsgeschichte der Testamente der Zwölf Patriarchen, Leiden 1970, págs. 373-400). Y el Testamento de Job para Spittler es «in fact a valuable monument , to the rich variety of hellenistic Jewish piety" (cf. J. H. CHARLESwORTH [ed.], The Old Testament Pseudepigrapha, I, pág. 836).

${ }^{34}$ Cf. B. LANG, "No Sex in Heaven: The Logic of Procreation, Death, and Eternal Life in the Judaeo-Christian Tradition", en A. CAQUot - S. LEgasse - M. TARDIEU, (eds.), Mélanges bibliques et orientaux en l'honneur de M. Mathias Delcor, Neukirchen - Vluyn 1985, 237-253. 
terrestre frente a la órbita celeste. Muerte, sexualidad y procreación se ven, pues, como resultado del pecado. Pero en el mundo divino y angélico ni se engendra ni se muere ${ }^{35}$. Esta mentalidad saldrá a la luz abiertamente en algunos círculos gnósticos que abogan por la desaparición del sexo femenino como condición indispensable para la entrada en el Reino. Así el último logion del Evangelio de Tomás: «Simón Pedro les dijo: que María nos deje porque las mujeres no son dignas de la vida, Jesús respondió: Yo mismo la guiaré para convertirla en varón, de forma que también ella pueda llegar a ser un espíritu viviente que se parezca a vosotros varones. Porque toda mujer que se convierta en varón entrará en el Reino de los Cielos" ${ }^{36}$.

Al dualismo apocalíptico se añade que, con el andar del tiempo, la atención del judaísmo se concentró cada vez más en la impureza como causa del mal y de la contaminación general de la naturaleza. $\mathrm{Y}$, en definitiva, se terminó por ver el sexo, en cuanto fuente primera de impureza, como causa principal del pecado. Esto ocurre no sólo en la comunidad de Qumrán sino también, por ejemplo, en el Testamento de Rubén. Dicha concepción contribuiría a exacerbar las corrientes misóginas puesto que la impureza quedaba reducida cada vez más a la impureza sexual ${ }^{37}$.

35 Cf. 1 Enoc 15,5-6: "Por eso les di mujeres, para que engendren y tengan hijos y nunca se acabe ninguna obra sobre la tierra. Pero vosotros erais espíritus vivientes y eternos, no mortales, por todas las generaciones de los siglos". Ver también Lc 20,3436. Y la concepción del celibato como anticipación de una vida futura sin sexo y de la creencia en una existencia asexuada.

36 Evangelio de Tomás, 114. "In the Gospel of Thomas the overcoming of sexual differentiation is portrayed as the goal of humankind in the eschatological era (in itself a Jewish and early Jewish-Christian motif, e.g., Mark 12:25). This view perhaps rests upon a belief in the original androgynous nature of humanity, to which eschatological humanity is to return", cf. R. SCROGGS, "Women in the New Testament", The Interpreter's Dictionary of the Bible. Supplementary Volume, Nashville, Abingdon 1976, pág. 968.

37 Cf. F. García Martínez, "Il problema della purità: la soluzione qumranica". En Israele alla ricerca di identità tra il III sec. a. C. e il I sec. d. C. Ricerche Storico Bibliche 1989, 169-191. Nótese que en la halakâ tradicional, el periodo de impureza de una mujer es más largo si ha dado a luz una hembra que si ha dado a luz un varón (ibid., pág. 189). Apocalipsis 14,4 celebra a los 144 mil que no se han manchado con mujeres. Cf. L. Fusella en Apocrifi dell'Antico Testamento, I, Torino 1981, págs. 206-207: “Col passare del tempo, invece, l’attenzione del giudeo si spostó sempre più dal fatto alla sua causa, cosicché centro dell'attenzione divenne il sesso, in quanto considerato fonte prima di ogni impurità. Non solo: poiché la contaminazione è conseguenza di peccato e avvio allo stesso, il sesso finisce un po' con l'essere visto como causa prima del peccato. Quest'idea si affermerà in pieno con l'autore del 'Testamenti dei Dodici Patriarchi', ma essa è già in nuce nel nostro autore" (es decir, 
El tabú y la inseguridad que rodean el fenómeno del sexo en algunas parcelas de la antigüedad, así como la pintura defensiva frente a la helenización que invade todas las capas de la sociedad y las esferas de la vida, llevan a los autores apocalípticos a concebir los cambios como transgresiones. Por eso, frente a la versatilidad humana y angélica se elogia la regularidad de los astros en el curso de sus órbitas y de los ciclos de la naturaleza. En cambio los Vigilantes han trastocado el orden celeste, asexuado, y el terrenal, confundiendo ambas esferas y trayendo el desorden a la tierra (1 Enoc 5-8) y este cataclismo ha sido causado por la seducción de las mujeres (TestRub 5,6-7).

Naturalmente, esta literatura radicalmente misógina no es exclusiva del judaísmo del s. I. La filosofía popular helenística y en concreto la escuela cínica, difundía aforismos de marcada hostilidad contra el sexo débil ${ }^{38}$. Y en el mundo rabínico de mediados del s. II d. C. una oración atribuida a Rabi Juda ben Elai decía así: «Tres bendiciones tiene el hombre que decir cada día: alabado sea el que no me hizo pagano. Alabado sea el que no me hizo mujer. Alabado sea el que no me hizo un inculto" ". Ahora bien, estos aforismos son producto y reflejo de la situación de inferioridad en que se encontraba la mujer en la sociedad antigua. Pero en ningún caso son comparables con los juicios éticos de condena del sexo femenino, elevados a categoría teológica en el contexto de una exégesis que quiere explicar y actualizar las palabras de la Escritura poniéndolas en consonancia con las orientaciones teológicas del judaísmo de la época. Dada, por otra parte, la popularidad de estos escritos, trans-

el autor del libro de los Jubileos). Cf. asimismo el excelente artículo de L. Rosso UBIGLI, «Alcuni aspetti della concezione della 'porneia' nel tardogiudaismo", Henoch I (1979) 201-245, para la literatura intertestamentaria y Filón. Para este último autor cf. R. A. BAER, Philo's Use of the Categories Male and Female, Leiden 1971. Ver también J. Maler, Zwischen den Testamenten, Geschichte und Religion in der Zeit des Zweiten Tempels, Würzburg 1990, pág. 223.

38 Cf. J. Leipol.DT, Die Frau in der Antike und im Urchristentum, Gütersloh 1963, pág. 58: Diógenes Laercio I, 33, transmite un dicho atribuido a Tales o a Sócrates según el cual dicho sabio estaba agradecido a la Fortuna por tres cosas: por ser un hombre y no un animal salvaje, por ser varón y no una mujer y por ser griego y no bárbaro. La dificultad de los antiguos en admitir el reconoçimiento de las mujeres - al menos en literatura - desencadenó sin duda el tópico de la mujer disfrazada de eunuco (Pelagia, Anastasia), donde la identidad sexual es aniquilada, cf. S. P. Brock and S. Ashbrook, Holy Women of the Syrian Orient, Los Angeles - London 1987, pág. 24.

${ }^{39}$ Cf. J. LeiPOLDT, Die Frau, pág. 58. 
mitidos casi íntegramente en medios cristianos, las consecuencias de una exégesis tan sesgada para la antropología judeo-cristiana difícilmente pueden sobrevalorarse.

\section{RESUMEN}

En el período helenístico el judaísmo dedicó un enorme esfuerzo a la reescritura de la historia y a la reinterpretación de las tradiciones bíblicas. El autor se centra en la nueva interpretación de la figura de algunas mujeres bíblicas tal como aparece en escritos del siglo primero, en especial la Vida Griega de Adán y Eva, los Testamentos de los Doce Patriarcas, el Testamento de Job y 4Q184. Intenta indagar en el trasfondo de dicha interpretación tal como se manifiesta en la literatura sapiencial y el pensamiento apocalíptico, e insiste en las consecuencias que dicha exégesis ideológica ha tenido para la antropología judeo-cristiana.

\section{SUMMARY}

In the Hellenistic period Judaism devoted much effort to the rewriting of history and to the new interpretation of Biblical traditions. The author focuses on the reinterpretation of the figure of Biblical women as it appears in some writings of the Ist century, especially the Greek Life of Adam and Eve, the Testaments of the Twelve Patriarchs, the Testament of Job and 4Q184. He intends to investigate the background and ideological support of this intepretation in the Wisdom Literature and the Apocalyptic representations. He also emphasizes the consequences that such an exegesis has had for the Judaeo-Christian anthropology. 